\title{
Periprocedural Peritonitis Prophylaxis: A Summary of the Microbiology and the Role of Systemic Antimicrobials
}

\author{
Leon Hsueh ${ }^{a, b}$ Susie L. Hu ${ }^{a, c}$ Ankur D. Shah ${ }^{a, c, d}$ \\ aWarren Alpert Medical School of Brown University, Providence, RI, USA; bepartment of Medicine, Rhode Island \\ Hospital, Providence, RI, USA; 'Division of Kidney Disease and Hypertension, Rhode Island Hospital, Providence, \\ RI, USA; ${ }^{d}$ Division of Nephrology, Medicine Service, Providence Veterans Affairs Medical Center, Providence, RI, USA
}

\section{Keywords \\ Periprocedure · Antibiotics · Peritoneal dialysis}

\begin{abstract}
Background: Peritonitis is a leading complication of peritoneal dialysis (PD). One strategy that the International Society for Peritoneal Dialysis (ISPD) has used to help mitigate the morbidity and mortality associated with peritonitis is through prevention, including antibiotic prophylaxis utilization in high-risk situations. The aim of this study is to summarize our current understanding of postprocedural peritonitis and discuss the existing data behind periprocedural antibiotic prophylaxis, focusing primarily on PD catheter insertion, dental procedures, colonoscopies, upper endoscopies with gastrostomy, and gynecologic procedures. Summary: The ISPD currently recommends intravenous antibiotics prior to PD catheter insertion, colonoscopies, and invasive gynecologic procedures, though prophylaxis has only demonstrated benefit in a prospective, randomized control setting for PD catheter insertion. However, multiple retrospective studies exist that support the use of antibiotic prophylaxis for the other 2 procedures. No specific antibiotic regimen has been established as most optimal to prevent
\end{abstract}

karger@karger.com www.karger.com/kdd

Karger $\frac{1}{\%}$

GOPEN ACCESS
(C) 2021 The Author(s)

Published by S. Karger AG, Basel

This is an Open Access article licensed under the Creative Commons Attribution-NonCommercial-4.0 International License (CC BY-NC) (http://www.karger.com/Services/OpenAccessLicense), applicable to the online version of the article only. Usage and distribution for commercial purposes requires written permission. peritonitis for any of the 3 procedures. Antibiotic coverage should include the Enterobacteriaceae family, as well as Gram-positive organisms commonly found on the skin flora for PD catheter insertion, anaerobes for colonoscopies, and common organisms from the urogenital flora in gynecologic procedures. Additionally, the ISPD currently recommends oral amoxicillin prior to dental procedures. There is currently no ISPD recommendation to provide antibiotic prophylaxis prior to an upper endoscopy with or without gastrostomy, though this is a potential area for research. Key Messages: PD patients are at high risk for developing peritonitis after typical procedures. Antibiotic prophylaxis is a potential strategy that the ISPD utilizes to prevent these infections. However, further research needs to be done to determine the optimal antibiotic regimen. 02021 The Author(s)

Published by S. Karger AG, Basel

\section{Introduction}

Peritonitis is a leading complication of peritoneal dialysis (PD) [1]. Peritonitis is associated with higher rates of conversion from PD to hemodialysis and mortality in the PD population [1]. End-stage kidney disease (ESKD) 
patients are already inherently at high risk for infections and sepsis-related mortality due to the effects of uremia on both innate and adaptive immunity [2]. Additionally, PD patients are at a high risk for peritonitis due to the presence of a long-term catheter in the peritoneal cavity [3]. One strategy that the International Society for Peritoneal Dialysis (ISPD) has used to help mitigate the morbidity and mortality associated with peritonitis is through prevention, including antibiotic prophylaxis utilization in high-risk situations [4]. However, there is great interfacility variability with regard to adherence to ISPD guidelines on antibiotic prophylaxis strategies [5]. The aim of this study is to summarize our current understanding of postprocedural peritonitis and discuss the existing data behind periprocedural antibiotic prophylaxis. We will focus on the procedures with the most published evidence, particularly PD catheter insertion, dental procedures, colonoscopies, upper endoscopies with gastrostomy, and gynecologic procedures.

\section{PD Catheter Insertion}

Exit site infections (ESIs) are a common cause of subsequent peritonitis in the $\mathrm{PD}$ population, with about $12 \%$ of cases of ESI progressing to peritonitis [3]. The majority of organisms cultured from ESIs are Gram positives commonly found on the skin, such as Staphylococcus aureus, coagulase-negative Staphylococcus spp., and Streptococcus spp. [6-8]. In one particular study of obese PD patients, Nessim et al. [7] found that these Gram positives made up $79 \%$ of ESIs but $55 \%$ of peritonitis, while Gram negatives made up only $7 \%$ of ESIs but $25 \%$ of peritonitis. Additionally, in an Italian study of 102 ESIs conducted in 1991 by Scalamogna et al. [6], S. aureus and Gram-negative infections were the only organisms that led to $\mathrm{PD}$ catheter removal. The most common Gram negatives that Scalamogna et al. [6] isolated were Pseudomonas aeruginosa, which made up $7.8 \%$ of cases, and Escherichia coli, which made up $3.9 \%$ of cases. Nessim et al. [7] did not report the specific Gram negatives that were cultured. Anaerobes seem to be infrequent causes of peritonitis from ESIs, making up only $0.7 \%$ of cases in a Canadian study published in 2010 by Hildebrand et al. [8] comparing First Nation and non-First Nation individuals. Given the high prevalence of Gram-positive ESIs and the high rates of peritonitis and subsequent complications from Gram-negative ESIs, potential regimens for prophylaxis likely should cover Gram positives from the skin, as well as those from the Enterobacteriaceae family.

Periprocedural Peritonitis Prophylaxis
The ISPD currently recommends multiple strategies to prevent ESI, especially during the catheter insertion, with the hope that preventing ESIs will decrease the risk of peritonitis. Of particular interest to this review is the grade $1 \mathrm{~A}$ recommendation from the 2016 ISPD guidelines to administer systemic antibiotics prior to catheter insertion, though a specific antibiotic regimen is not listed [4]. This recommendation is based on 4 randomized controlled trials comparing perioperative IV antibiotics with no antibiotics and the resulting systematic review of these studies [9]. Lye et al. [10] found in a study of 50 patients no benefit from giving intravenous (IV) cefazolin and gentamicin prior to PD catheter insertion. However, the other 3 studies demonstrated a positive result when comparing antibiotics head-to-head with no antibiotics. They were conducted by Bennett-Jones et al., who examined in 27 patients IV gentamicin versus no antibiotics, Wikdahl et al. [12] who studied in 38 patients the combination of IV cefuroxime preoperatively and intraperitoneal cefuroxime perioperatively versus no antibiotics, and Gadallah et al. [11] who compared IV vancomycin with both IV cefazolin and no antibiotics in 221 patients undergoing 254 PD catheter placements [11-13]. Interestingly, Gadallah et al. [11] found that vancomycin did better than cefazolin in preventing peritonitis, even though vancomycin lacks the Gram-negative coverage that is present from cefazolin. This observation can potentially be explained by the fact that of the 17 patients that suffered peritonitis after PD catheter insertion in the study, only 4 cases were not from a Gram-positive organism; 3 were culture negative; and 1 was due to Enterobacter cloacae [11]. Overall, based on these 4 trials, it appears that systemic antibiotics perioperatively likely would provide benefit during PD catheter insertions, though further research has to be conducted to identify the most appropriate regimen.

Once the PD catheter is inserted, there is debate about the optimal time to initiate $\mathrm{PD}$, though it appears there are higher rates of peritoneal fluid leaks when PD is initiated at 1 week from catheter insertion compared to waiting 2-3 weeks based on the Timely PD study $[14,15]$. Leaks are associated with ESIs and peritonitis [16]. In one retrospective review of 79 leaks in 66 patients, Holley et al. [17] found that $42 \%$ of leaks were associated with some form of infection either before or after a leak was observed, and even with prophylactic antibiotics, 11 of the 66 patients developed a postleak infection. Given the high risk for infection, leaks should be avoided, and if present, antibiotics should probably be given prophylactically while an infectious workup is completed to rule out peritonitis or ESI. 


\section{Dental Procedures}

The ESKD population has severe oral disease compared to the general population, which can result in systemic consequences [18]. A multinational collaboration of investigators prospectively enrolled 4,726 hemodialysis patients between 2010 and 2012 into the ORAL-D cohort study and found that edentulousness, tooth decay, missing teeth, and filled teeth are associated with a higher rate of early death [19]. However, it is difficult to determine if this correlative relationship has more to do with the fact that dental disease is associated with lower socioeconomic status, reduced receptiveness to healthcare engagement, and lower health literacy, which, in turn, are linked to mortality $[20,21]$. When propensity matched, there does not appear to be a link between periodontitis and both all-cause mortality and cardiovascular mortality [22]. Regular visits to a dental practitioner are a potential method for intervening on the poor oral care seen in ESKD patients.

Dental procedures, however, are not without their own risks. Dental procedures are associated with both transient bacteremia and endocarditis, likely from the tissue trauma that open up small blood vessels to bacterial entry [23]. In the PD population, this bacteremia can lead to peritonitis. Streptococcus spp. are the most common organisms cultured from odontogenic bacteremic patients after dental procedure [24]. In particular, Streptococcus viridans is the predominant organism seen in PD patients with postdental procedure peritonitis [25-27].

Patients with high risk for endocarditis, like those with prosthetic heart valves or unrepaired congenital cyanotic diseases, are well known to require antibiotic prophylaxis prior to dental procedures. One dose of amoxicillin $2 \mathrm{~g}$, or clindamycin $600 \mathrm{mg}$ for penicillin-allergic patients, is given for prophylaxis 30-60 min prior to a dental procedure in these patients [28]. PD patients are a lesser known population that should receive antibiotic prophylaxis to prevent peritonitis associated with the transient bacteremia from dental procedures [4]. In fact, in a survey completed in 2004 with nephrologists in Australia and New Zealand, only $41 \%$ of respondents recommended antibiotic prophylaxis for dental procedures [29]. ISPD guidelines from 2016 suggest using a single oral dose of amoxicillin as the prophylaxis regimen, similar to that used in the patients at high risk for endocarditis, as described above, though data are limited to support this recommendation [4]. The American Dental Association currently has no specific guidelines for antibiotic prophylaxis in PD patients. However, given the high morbidity and mortal- ity associated with peritonitis and the relatively low risk of a single dose of amoxicillin, providers should recommend antibiotic prophylaxis in PD patients undergoing dental procedures.

\section{Colonoscopy}

As a part of the American Board of Internal Medicine's Choosing Wisely campaign and in accordance with the American College of Physicians' recommendation against screening in patients with life expectancies of $<10$ years, the American Society of Nephrology generally does not recommend colorectal cancer screening in ESKD patients on maintenance dialysis due to their limited life expectancies once they reach the age of 50 [30]. However, colonoscopies are still a common procedure both in the inpatient and outpatient setting, especially given the higher rates of gastrointestinal bleeding in ESKD patients compared to the general population [31]. Kidney transplant candidates, in particular, continue to be screened for colorectal cancer as well, a disproportionate percentage of whom are on PD as a dialysis modality [30]. There is growing literature that colonoscopy increases the risk of peritonitis in the PD population [32-34]. Mucosal disruption and subsequent seeding of the peritoneum is the most frequently proposed mechanism $[25,32]$. The rate of peritonitis after colonoscopies without antibiotic prophylaxis in PD patients has been reported to be between 4 and 8\% [32-34]. Colonic biopsies do not appear to increase the risk for peritonitis any further, but there have been conflicting data about whether polypectomies increase this risk [32-34]. As it is not possible to determine which patients will undergo polypectomies during their colonoscopy, all patients are treated as if they will undergo a polypectomy.

The most frequent culprit organisms cultured from the peritoneal fluid are from the Enterobacteriaceae family, especially E. coli (shown in Table 1; online suppl. Table 1; see www.karger.com/doi/10.1159/000513773 for all online suppl. material). Treatment most commonly includes a first-generation cephalosporin plus an aminoglycoside, which is an ISPD guideline-recommended empiric antibiotic regimen for peritonitis [4, 32]. However, there are cases of other organisms from the gut flora, particularly anaerobes, like Bacteroides spp., that would not be covered by this empiric therapy [35]. In patients who do not improve with ISPD guideline-directed antibiotic therapy for peritonitis, providers should consider expanding antibiotic coverage to include anaerobes. 
Table 1. Summary of published cases of peritonitis in PD patients after colonoscopy

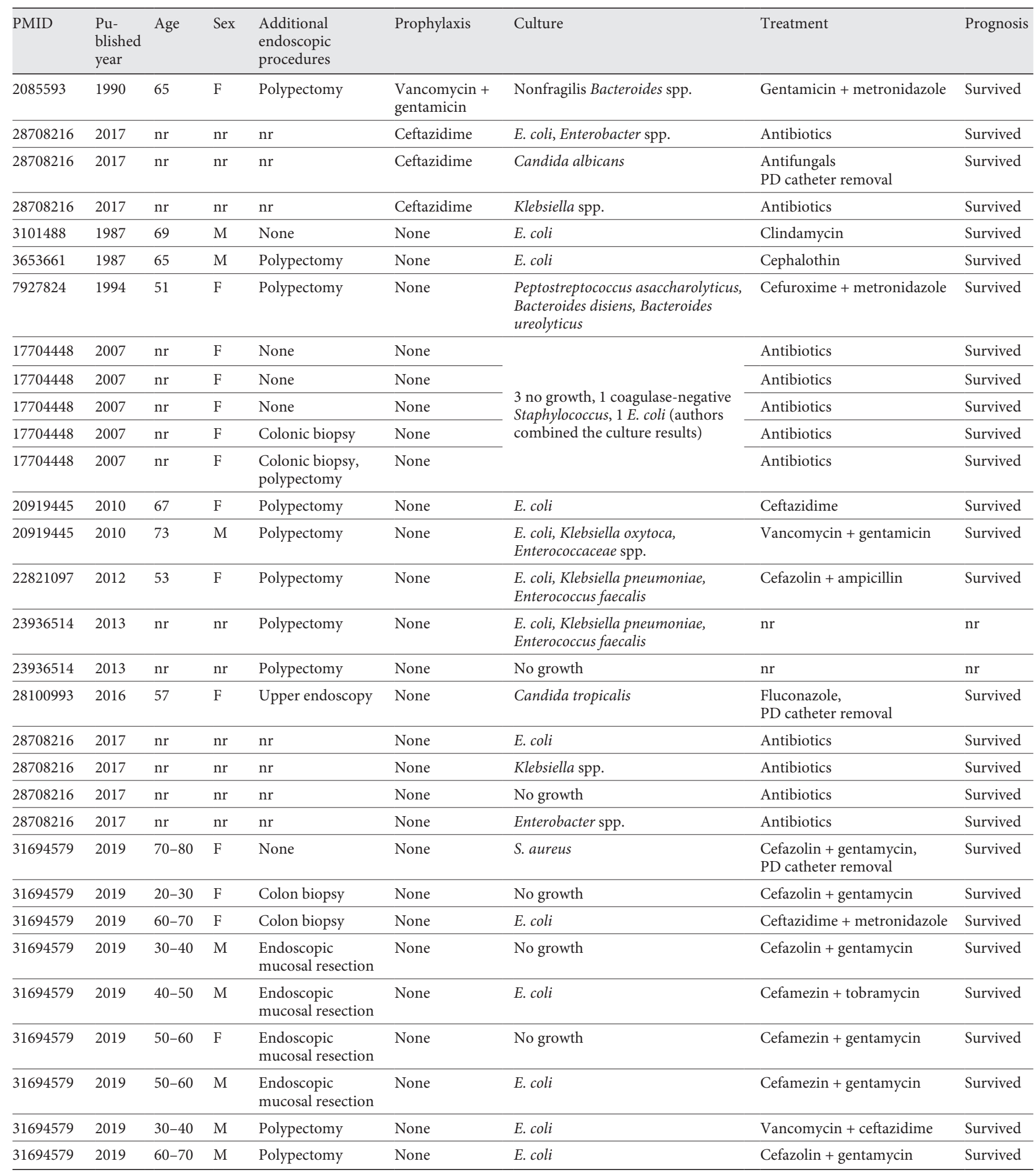

Listed treatments were the final antibiotics selected after the result of culture data. "Antibiotics" were listed for treatment if the authors did not specify the name of the antibiotic chosen. References are listed in the online suppl. material. PD, peritoneal dialysis; nr, not reported. 
Additionally, there are rare cases of fungal peritonitis associated with colonoscopies, which also would not be covered by the above empiric therapy and would portend to a higher mortality rate $[25,36]$. Due to the high morbidity and mortality associated with fungal infections, the ISPD does recommend either oral nystatin or oral fluconazole for prophylaxis in patients who are exposed to a prolonged course of antibiotics, which is a known risk factor for developing fungal peritonitis, irrespective of whether or not there is a planned procedure $[4,25]$. Colonoscopies are not a known independent risk factor for fungal peritonitis. However, fungal peritonitis has to be considered, as well, if patients do not improve with the above ISPD guideline-directed antibiotic therapy for peritonitis, especially if they recently underwent antibiotic therapy for another bacterial infection.

With regard to prevention, there is one known published randomized control study of $93 \mathrm{PD}$ patients performed by Al-Hwiesh et al. [34] who found no benefit for the use of only ceftazidime for prophylaxis prior to colonoscopy. However, ceftazidime lacks coverage for anaerobic organisms that can be seen in pericolonoscopy peritonitis, as well as for many Gram positives [37].

There are 3 other retrospective studies that compared the rates of peritonitis in patients who received pericolonoscopy antibiotics with patients who did not. Yip et al. [33] reviewed 97 colonoscopies in 77 PD patients and found 5 cases of postprocedure peritonitis, none of which were the 18 cases who received some form of periprocedure antibiotics. Gweon et al. [32] also retrospectively observed that none of their $65 \mathrm{PD}$ patients who received prophylactic antibiotics developed peritonitis after colonoscopy, compared to 9 who suffered from peritonitis out of the 172 patients who did not receive prophylactic antibiotics. Both retrospective observations were not statistically significant, likely due to their small sample sizes. Lastly, in a retrospective study of all gastrointestinal and gynecologic endoscopies, Wu et al. [38] found a statistical significance in reducing peritonitis rates in patients who received prophylactic antibiotics prior to nonesophagogastroduodenoscopy endoscopies, including colonoscopies. All 3 retrospective studies suggest that utilizing pericolonoscopy antibiotics has the potential to prevent postprocedural peritonitis.

However, the specific antibiotic regimen in these studies was quite heterogeneous. Gweon et al. [32] did not report the specific periprocedure antibiotics that were used, but Yip et al. [33] reported 14 different antibiotic regimens among the 18 cases who received antibiotics prior to a colonoscopy, 6 of which received cephalosporin monoprophylaxis, 5 of which received an aminoglycoside as a part of their regimen, and 4 of which received levofloxacin $[32,33]$. Among the 4 patients who received levofloxacin, 3 received the antibiotic by itself while another received it as a part of tuberculosis treatment $[32,33]$. On the other hand, Wu et al. [38] reported that among the 5 patients who received antibiotics prior to their colonoscopy, 3 got a dose of ceftriaxone [38].

Nonetheless, in response to the increased risk of peritonitis after colonoscopy, the ISPD recommends prophylactic antibiotics for any PD patient prior to undergoing a colonoscopy [4]. This 2016 guideline does not recommend a specific antibiotic choice but cites a single dose of IV ampicillin plus an aminoglycoside, with or without metronidazole, as a potential regimen, citing a previous systematic review, although it should be noted that this systematic review did not specifically mention or suggest this regimen $[4,9]$. This prophylactic regimen would generally cover the organisms described above that most commonly cause peritonitis. Additionally, the abdomen should be empty of fluid prior to the procedure $[25,39]$. Citing a 2011 ISPD position paper, the 2015 American Society for Gastrointestinal Endoscopy (ASGE) guidelines also recommend prophylactic antibiotics prior to a colonoscopy in PD patients but do not suggest any specific regimen [40].

The recommendations developed in conjunction between the American Society of Health-System Pharmacists (ASHP), the Infectious Diseases Society of America (IDSA), the Surgical Infection Society (SIS), and the Society for Healthcare Epidemiology of America (SHEA) in 2013 for antibiotic prophylaxis prior to colorectal surgery may also provide guidance on the appropriate antibiotic regimen prior to a colonoscopy. Citing a Cochrane systematic review of 182 studies in 2009 that has since been updated to 260 trials in 2014, these guidelines recommend using an antibiotic regimen with activity against anaerobic and aerobic floras of the bowel prior to colorectal surgery, such as cefazolin plus metronidazole, cefoxitin, cefotetan, ampicillin-sulbactam, or ceftriaxone plus metronidazole in regions with high Gram-negative resistance to first- and second-generation cephalosporins [41, 42]. Similar to postcolonoscopy peritonitis, the most common culprit organisms seen in infections after colorectal surgery are E. coli and anaerobes, like Bacteroidesfragilis [43]. Given the similar bacteriology, this guideline has potential applications to determining an appropriate antibiotic regimen prior to colonoscopies in $\mathrm{PD}$ patients. 
Table 2. Summary of published cases of peritonitis in PD patients after upper endoscopy

\begin{tabular}{|c|c|c|c|c|c|c|c|c|}
\hline PMID & $\begin{array}{l}\text { Published } \\
\text { year }\end{array}$ & Age & Sex & $\begin{array}{l}\text { Additional endoscopic } \\
\text { procedures }\end{array}$ & Prophylaxis & Culture & Treatment & Prognosis \\
\hline 11510264 & 2001 & 66 & $\mathrm{~F}$ & PEG placement & None & Candida spp. & $\mathrm{nr}$ & Deceased \\
\hline 11510264 & 2001 & 37 & $\mathrm{M}$ & PEG placement & None & Klebsiella spp. & Antibiotics & Survived \\
\hline 11510264 & 2001 & 81 & $\mathrm{~F}$ & PEG placement & None & $\mathrm{nr}$ & Antibiotics & Survived \\
\hline 11510264 & 2001 & 64 & $\mathrm{M}$ & PEG placement & None & Candida spp. & $\mathrm{nr}$ & Deceased \\
\hline 11510264 & 2001 & 58 & $\mathrm{M}$ & PEG placement & None & Polymicrobial including fungal & $\mathrm{nr}$ & Deceased \\
\hline 16686285 & 2005 & 69 & M & $\begin{array}{l}\text { Epinephrine injection, } \\
\text { heat-probe coagulation } \\
\text { of a bleeding ulcer }\end{array}$ & None & Streptococcus viridans & $\begin{array}{l}\text { Ceftazidime, } \\
\text { clarithromycin }\end{array}$ & Survived \\
\hline 21084055 & 2010 & 49 & $\mathrm{~F}$ & None & None & Enterococcus faecalis & $\begin{array}{l}\text { Imipenem/cilastatin + } \\
\text { vancomycin }\end{array}$ & Survived \\
\hline 23936514 & 2013 & $\mathrm{nr}$ & $\mathrm{nr}$ & Local hemostasis & None & E. coli & $\mathrm{nr}$ & $\mathrm{nr}$ \\
\hline 25228218 & 2014 & 28 & $\mathrm{M}$ & None & None & $\begin{array}{l}\text { Klebsiella pneumoniae, Morganella } \\
\text { morganii, Bacteroides fragilis, } \\
\text { Prevotella spp., Clostridium } \\
\text { clostridioforme, Citrobacter koseri, } \\
\text { Enterococcus faecium }\end{array}$ & $\begin{array}{l}\text { Vancomycin }+ \\
\text { tobramycin }+ \\
\text { metronidazole, } \\
\text { PD catheter removal }\end{array}$ & Deceased \\
\hline 25228218 & 2014 & 73 & $\mathrm{M}$ & $\begin{array}{l}\text { Epinephrine injection, } \\
\text { placement of multiple clips }\end{array}$ & None & E. coli & Ciprofloxacin & Survived \\
\hline 26483616 & 2015 & 50 & $\mathrm{M}$ & $\begin{array}{l}\text { Duodenal ulcer biopsy, } \\
\text { colonoscopy }\end{array}$ & None & Coagulase-negative Staphylococcus & $\begin{array}{l}\text { Vancomycin }+ \\
\text { cefepime }\end{array}$ & Survived \\
\hline 28100993 & 2016 & 57 & $\mathrm{~F}$ & Colonoscopy & None & Candida tropicalis & $\begin{array}{l}\text { Fluconazole, } \\
\text { PD catheter removal }\end{array}$ & Survived \\
\hline
\end{tabular}

Listed treatments were the final antibiotics selected after the result of culture data. "Antibiotics" were listed for treatment if the authors did not specify the name of the antibiotic chosen. References are listed in the online suppl. material. PD, peritoneal dialysis; nr, not reported; PEG, percutaneous endoscopic gastrostomy.

\section{Upper Endoscopy with Gastrostomy}

There currently is little data to support the benefit of prophylactic antibiotics in upper endoscopies alone compared with colonoscopies. In fact, the ISPD 2016 guidelines do not recommend the use of antibiotic prophylaxis prior to an upper endoscopy $[4,25]$. Additionally, $\mathrm{Wu}$ et al. [38] in 2013 found that upper endoscopies had significantly lower rates of peritonitis compared to other types of endoscopic procedures in PD patients [38].

However, there is growing literature that demonstrates a relationship between percutaneous endoscopic gastrostomy (PEG) placement and postprocedure peritonitis in PD patients [44]. Given that malnutrition is a known risk factor for mortality in the ESKD population, PEG placements may start to become more common, especially in younger individuals on $\mathrm{PD}$ who need to be bridged to a kidney transplant [45]. The mechanism for developing peritonitis in upper endoscopies with PEG placements is likely similar to that for colonoscopies given the significant amount of air insufflation and the puncturing of the abdominal wall required for PEG placements [46]. Interestingly, the risk of peritonitis is not present in PD patients who received their PEG prior to initiating PD [44].

Organisms commonly cultured in the peritoneal fluid after PEG placement are similar to those found after colonoscopy (shown in Table 2; online suppl. Table 2). Additionally, fungal peritonitis is a rare occurrence after PEG placement [47]. There have also been case reports of peritonitis with cultures positive for oral flora like Streptococcus viridans $[48,49]$. Fortunately, oral flora, like Streptococcus viridans, tends to be susceptible to the ISPD-recommended empiric therapy for peritonitis. Nevertheless, the literature continues to be sparse about the presence of a benefit to antibiotic prophylaxis prior to an upper endoscopy with or without a PEG placement, and the ISPD 2016 guidelines do not specify using antibiotic prophylaxis in the setting of an upper endoscopy [4, 38]. The 2015 ASGE guidelines, however, do recommend administering cefazolin prior to an upper endoscopy with PEG placement for all patients [40]. Similar to prior to a 
Table 3. Summary of published cases of peritonitis in PD patients after gynecologic procedures

\begin{tabular}{|c|c|c|c|c|c|c|c|}
\hline PMID & $\begin{array}{l}\text { Published } \\
\text { year }\end{array}$ & Age & Procedure & $\begin{array}{l}\text { Pro- } \\
\text { phylaxis }\end{array}$ & Culture & Treatment & Prognosis \\
\hline 8465827 & 1993 & 42 & Hysteroscopy & None & $\begin{array}{l}\text { Group B Streptococcus, } \\
\text { Candida albicans }\end{array}$ & $\begin{array}{l}\text { Vancomycin, amphotericin B + } \\
\text { flucytosine, PD catheter removal }\end{array}$ & Deceased \\
\hline 9284475 & 1997 & 41 & $\begin{array}{l}\text { Hysteroscopy with uterine } \\
\text { polypectomy }\end{array}$ & None & Candida glabrata & $\begin{array}{l}\text { Fluconazole + isoconazole, PD } \\
\text { catheter removal }\end{array}$ & Survived \\
\hline 19293366 & 2009 & 41 & $\begin{array}{l}\text { Hysteroscopy with } \\
\text { endometrial ablation }\end{array}$ & None & $\begin{array}{l}\text { Group B Streptococcus, } \\
\text { methicillin-sensitive } \\
\text { S. aureus, E. coli }\end{array}$ & $\begin{array}{l}\text { Ceftazidime }+ \text { amikacin }+ \\
\text { vancomycin, PD catheter removal }\end{array}$ & $\begin{array}{l}\text { Septic shock } \\
\text { but survived }\end{array}$ \\
\hline \multirow[t]{3}{*}{$21084055^{\mathrm{a}}$} & \multirow[t]{3}{*}{2010} & \multirow[t]{3}{*}{49} & Gynecologic physical exam & None & Enterococcus spp. & Imipenem/cilastatin + amikacin & Survived \\
\hline & & & Gynecologic physical exam & None & No growth & Imipenem/cilastatin + amikacin & Survived \\
\hline & & & Gynecologic physical exam & None & Gram-positive cocci & Imipenem/cilastatin + amikacin & Survived \\
\hline $22302931^{\mathrm{a}}$ & 2012 & 41 & $\begin{array}{l}\text { Cervical conization, } \\
\text { endocervical curettage } \\
\text { under colposcopy }\end{array}$ & None & $\begin{array}{l}\text { Stenotrophomonas } \\
\text { maltophilia }\end{array}$ & Cefazolin + gentamicin & Survived \\
\hline 24133084 & 2013 & 29 & $\begin{array}{l}\text { Laparoscopy with removal } \\
\text { of a migrating IUD }\end{array}$ & None & Comamonas testosteroni & Ciprofloxacin & Survived \\
\hline $23936514^{\mathrm{b}} / 31028109$ & $2013 / 2019$ & 27 & Hysteroscopy & None & No growth & Cefazolin + gentamicin & Survived \\
\hline $23936514^{\mathrm{b}} / 31028109$ & $2013 / 2019$ & 58 & $\begin{array}{l}\text { Hysteroscopy with } \\
\text { endometrial curettage }\end{array}$ & None & No growth & Cefazolin + gentamicin & Survived \\
\hline $23936514^{\mathrm{b}} / 31028109$ & $2013 / 2019$ & 38 & IUD insertion & None & Group B Streptococcus & Vancomycin + ceftazidime & Survived \\
\hline $23936514^{\mathrm{b}} / 31028109$ & $2013 / 2019$ & 45 & IUD insertion & None & Enterococcus faecalis & Ceftriaxone + vancomycin & Survived \\
\hline $23936514^{\mathrm{b}} / 31028109$ & $2013 / 2019$ & 45 & IUD removal & None & $\begin{array}{l}\text { Group D Streptococcus, } \\
\text { E. coli }\end{array}$ & $\begin{array}{l}\text { Cefazolin + gentamicin, } \\
\text { ceftriaxone }\end{array}$ & Survived \\
\hline 31028109 & 2019 & 37 & $\begin{array}{l}\text { Hysteroscopy with } \\
\text { polypectomy }\end{array}$ & None & No growth & Cefazolin + ceftazidime & Survived \\
\hline
\end{tabular}

Listed treatments were the final antibiotics selected after the result of culture data. References are listed in the online suppl. material. PD, peritoneal dialysis; $\mathrm{nr}$, not reported; IUD, intrauterine device. ${ }^{\mathrm{a}}$ Both studies presented a single patient with multiple episodes of peritonitis. ${ }^{\mathrm{b}}$ Two studies presented the same patients. Each publication provided different data for this table.

colonoscopy, patients planning to undergo any upper endoscopy would benefit from keeping the abdomen dry prior to the procedure [25].

\section{Gynecologic Procedures}

Due to the proximity of the pelvis to the abdominal cavity, gynecologic procedures are suspected to increase the risk for peritonitis in PD patients [4, 25]. A diverse variety of gynecologic procedures have been reported to cause peritonitis, including pap smears, diagnostic hysteroscopies, endometrial polypectomies, endometrial curettages, cervical conizations, and both intrauterine device (IUD) implantations and removals $[38,50,51]$. The most commonly reported organisms in the literature include Gram-negative bacilli, Enterococcus and Streptococcus, which are similar to the ones that are found most frequently in genitourinary tract infections (shown in Table 3; online suppl. Table 3). Due to the high prevalence of Candida in the mucosal surfaces of the external genitalia, it is not surprising that there has also been multiple reports of Candida peritonitis in PD patients who underwent gynecologic procedures [52-54]. Periprocedural fungal prophylaxis is not currently a guideline recommendation, but it could be considered in those known to have candidiasis.

Due to the concern for peritonitis, the ISPD 2016 guidelines recommend antibiotic prophylaxis in all patients undergoing invasive gynecologic procedures. They 
suggest the same antibiotic regimen as that for colonoscopies: a single dose of IV ampicillin plus an aminoglycoside, with or without metronidazole [4]. The American College of Obstetricians and Gynecologists (ACOG) does not have a specific guideline for $\mathrm{PD}$ patients but recommends, in the general population, cefazolin prior to any hysterectomy or laparotomy and doxycycline prior to any uterine evacuations, like dilation and curettage [55].

The available data for prophylaxis in the setting of gynecologic procedures are weaker than the data for colonoscopies in PD patients $[4,50]$. Two small retrospective studies did find that patients who received prophylactic antibiotics were able to avoid postprocedure peritonitis, though only one of the studies reached statistical significance when comparing peritonitis rates with patients who did not receive antibiotic prophylaxis prior to a gynecologic procedure $[38,50]$. The prophylactic antibiotic regimen of choice was heterogeneous across both studies. $\mathrm{Wu}$ et al. [38] reported the use of oral clindamycin for 2 dilatation and curettages, as well as 1 hysteroscopy, and oral cefadroxil for a third reported dilatation and curettage. In contrast, Fan et al. [50] reported the use of 7 different prophylactic antibiotic regimens, with the most utilized one being oral cefadroxil $500 \mathrm{mg}$ once daily for 3 days. Although there are no data, antibiotic prophylaxis is strongly suggested prior to childbirth, with most deliveries described in the literature requiring a caesarean section [56]. Similar to the 2 other abdominopelvic procedures discussed above, gynecologic procedures also require an empty peritoneal cavity to minimize the risk of peritonitis [56].

\section{Conclusion}

PD patients are at high risk for developing peritonitis after commonly routine procedures. The role of antibiotics in PD catheter insertion has been studied prospectively, but only small retrospective studies have looked at the benefits of antibiotic prophylaxis in other routine procedures. Additionally, the antibiotics chosen are quite heterogeneous within and across the different studies. Given the limits of the evidence in the PD population, there may be benefit in evaluating antibiotic prophylaxis recommendations from other societies and attempt to apply them to the setting of PD patients. For example, prior to dental procedures, the ISPD has adopted strategies for PD patients to prevent peritonitis with amoxicillin similar to that used by the American Heart Association to prevent endocarditis in high-risk patients. ISPD currently suggests ampicillin plus an aminoglycoside, with or without metronidazole, prior to colonoscopies or gynecologic procedures. Potential alternatives to consider could be derived from the Surgical Infection Society (SIS) and IDSA guidelines for colorectal surgery due to the common bacteriology between postcolorectal surgical infections and PD-related peritonitis. Most cases in the literature report culprit organisms that would have been susceptible to either antibiotic regimen (shown in Tables 1-3; online suppl. Tables 1-3). Antibiotic prophylaxis prior to upper endoscopy is not currently recommended, but prophylaxis prior to PEG placement due to the violation of the peritoneum would likely be beneficial. Nonetheless, moving forward, large prospective trials will be useful for discerning the true benefits of periprocedural antibiotics, as well as the optimal regimen.

\section{Statement of Ethics}

The authors have no ethical conflicts of interest to disclose.

\section{Conflict of Interest Statement}

The authors report no relevant conflicts of interest.

\section{Funding Sources}

The authors declared that they have no relevant financial interests.

\section{Author Contributions}

Each author contributed important intellectual content during manuscript drafting or revision and accepts accountability for the overall work by ensuring that questions pertaining to the accuracy or integrity of any portion of the work are appropriately investigated and resolved.

\section{Disclaimer}

The views expressed in this article are those of the authors and do not necessarily reflect the position or policy of the US Department of Veterans Affairs or the US government. 


\section{References}

1 Ye H, Zhou Q, Fan L, Guo Q, Mao H, Huang $\mathrm{F}$, et al. The impact of peritoneal dialysis-related peritonitis on mortality in peritoneal dialysis patients. BMC Nephrol. 2017;18(1): 186.

2 Cohen G, Haag-Weber M, Hörl WH. Immune dysfunction in uremia. Kidney Int Suppl. 1997;62:S79-82.

3 Akoh JA. Peritoneal dialysis associated infections: an update on diagnosis and management. World J Nephrol. 2012;1(4):106-22.

4 Li PK, Szeto CC, Piraino B, de Arteaga J, Fan $\mathrm{S}$, Figueiredo AE, et al. ISPD peritonitis recommendations: 2016 update on prevention and treatment. Perit Dial Int. 2016;36(5):481508.

5 Boudville N, Johnson DW, Zhao J, Bieber BA, Pisoni RL, Piraino B, et al. Regional variation in the treatment and prevention of peritoneal dialysis-related infections in the Peritoneal Dialysis Outcomes and Practice Patterns Study. Nephrol Dial Transplant. 2019;34(12): 2118-26.

6 Scalamogna A, Castelnovo C, De Vecchi A, Ponticelli C. Exit-site and tunnel infections in continuous ambulatory peritoneal dialysis patients. Am J Kidney Dis. 1991;18(6): 674-7.

7 Nessim SJ, Komenda P, Rigatto C, Verrelli M, Sood MM. Frequency and microbiology of peritonitis and exit-site infection among obese peritoneal dialysis patients. Perit Dial Int. 2013;33(2):167-74.

8 Hildebrand A, Komenda P, Miller L, Rigatto C, Verrelli M, Sood AR, et al. Peritonitis and exit site infections in First Nations patients on peritoneal dialysis. Clin J Am Soc Nephrol. 2010;5(11):1988-95.

9 Strippoli GF, Tong A, Johnson D, Schena FP, Craig JC. Antimicrobial agents to prevent peritonitis in peritoneal dialysis: a systematic review of randomized controlled trials. Am J Kidney Dis. 2004;44(4):591-603.

10 Lye WC, Lee EJ, Tan CC. Prophylactic antibiotics in the insertion of Tenckhoff catheters. Scand J Urol Nephrol. 1992;26(2):177-80.

11 Gadallah MF, Ramdeen G, Mignone J, Patel D, Mitchell L, Tatro S. Role of preoperative antibiotic prophylaxis in preventing postoperative peritonitis in newly placed peritoneal dialysis catheters. Am J Kidney Dis. 2000; 36(5):1014-9.

12 Wikdahl AM, Engman U, Stegmayr BG, Sörenssen JG. One-dose cefuroxime i.v. and i.p. reduces microbial growth in $\mathrm{PD}$ patients after catheter insertion. Nephrol Dial Transplant. 1997;12(1):157-60.

13 Bennet-Jones DN, Martin J, Barratt AJ, Duffy TJ, Naish PF, Aber GM. Prophylactic gentamicin in the prevention of early exit-site infections and peritonitis in CAPD. Adv Perit Dial. 1988;4:147-50.

14 Ranganathan D, John GT, Yeoh E, Williams $\mathrm{N}$, O'Loughlin B, Han T, et al. A randomized controlled trial to determine the appropriate time to initiate peritoneal dialysis after insertion of catheter (Timely PD Study). Perit Dial Int. 2017;37(4):420-8.

15 Szeto CC, Li PK, Johnson DW, Bernardini J, Dong J, Figueiredo AE, et al. ISPD catheterrelated infection recommendations: 2017 update. Perit Dial Int. 2017;37(2):141-54.

16 Leblanc M, Ouimet D, Pichette V. Dialysate leaks in peritoneal dialysis. Semin Dial. 2001; 14(1):50-4.

17 Holley JL, Bernardini J, Piraino B. Characteristics and outcome of peritoneal dialysate leaks and associated infections. Adv Perit Dial. 1993;9:240-3.

18 Costantinides F, Castronovo G, Vettori E, Frattini C, Artero ML, Bevilacqua L, et al. Dental care for patients with end-stage renal disease and undergoing hemodialysis. Int J Dent. 2018;2018:9610892.

19 Palmer SC, Ruospo M, Wong G, Craig JC, Petruzzi M, De Benedittis M, et al. Dental health and mortality in people with end-stage kidney disease treated with hemodialysis: a multinational cohort study. Am J Kidney Dis. 2015; 66(4):666-76

20 Cavanaugh KL, Wingard RL, Hakim RM, Eden S, Shintani A, Wallston KA, et al. Low health literacy associates with increased mortality in ESRD. J Am Soc Nephrol. 2010; 21(11):1979-85.

21 Grubbs V, Plantinga LC, Tuot DS, Powe NR. Chronic kidney disease and use of dental services in a United States public healthcare system: a retrospective cohort study. BMC Nephrol. 2012;13:16.

22 Ruospo M, Palmer SC, Wong G, Craig JC, Petruzzi M, De Benedittis M, et al. Periodontitis and early mortality among adults treated with hemodialysis: a multinational propensitymatched cohort study. BMC Nephrol. 2017; 18(1): 166

23 Lockhart PB, Brennan MT, Sasser HC, Fox PC, Paster BJ, Bahrani-Mougeot FK. Bacteremia associated with toothbrushing and dental extraction. Circulation. 2008;117(24):311825.

24 Parahitiyawa NB, Jin LJ, Leung WK, Yam WC, Samaranayake LP. Microbiology of odontogenic bacteremia: beyond endocarditis. Clin Microbiol Rev. 2009;22(1):46-64.

25 Dhruve MJ, Bargman JM. Antibiotic prophylaxis in peritoneal dialysis patients. Adv Perit Dial. 2017;33(2017):55-8.

26 Shukla A, Abreu Z, Bargman JM. Streptococcal PD peritonitis: a 10-year review of one centre's experience. Nephrol Dial Transplant. 2006;21(12):3545-9.

27 Kiddy K, Brown PP, Michael J, Adu D. Peritonitis due to Streptococcus viridans in patients receiving continuous ambulatory peritoneal dialysis. Br Med J. 1985;290(6473): 969-70.

28 Wilson W, Taubert KA, Gewitz M, Lockhart PB, Baddour LM, Levison M, et al. Prevention of infective endocarditis: guidelines from the
American Heart Association: a guideline from the American Heart Association Rheumatic Fever, Endocarditis, and Kawasaki Disease Committee, Council on Cardiovascular Disease in the Young, and the Council on Clinical Cardiology, Council on Cardiovascular Surgery and Anesthesia, and the Quality of Care and Outcomes Research Interdisciplinary Working Group. Circulation. 2007; 116(15):1736-54

29 Tong DC, Walker RJ. Antibiotic prophylaxis in dialysis patients undergoing invasive dental treatment. Nephrology. 2004;9(3):167-70.

30 Carlos CA, McCulloch CE, Hsu CY, Grimes B, Pavkov ME, Burrows NR, et al. Colon cancer screening among patients receiving dialysis in the United States: Are we choosing wisely? J Am Soc Nephrol. 2017;28(8): 2521-8.

31 Toke AB. GI bleeding risk in patients undergoing dialysis. Gastrointest Endosc. 2010; 71(1):50-2.

32 Gweon TG, Jung SH, Kim SW, Lee KM, Cheung DY, Lee BI, et al. Risk factors for peritonitis in patients on continuous ambulatory peritoneal dialysis who undergo colonoscopy: a retrospective multicentre study. BMC Gastroenterol. 2019;19(1):175.

33 Yip T, Tse KC, Lam MF, Cheng SW, Lui SL, Tang S, et al. Risks and outcomes of peritonitis after flexible colonoscopy in CAPD patients. Perit Dial Int. 2007;27(5):560-4.

34 Al-Hwiesh AK, Abdul-Rahman IS, Hussameldeen MA, Al-Audah N, Abdelrahman A, Moaigel HM, et al. Colonoscopy in automated peritoneal dialysis patients: value of prophylactic antibiotics: a prospective study on a single antibiotic. Int J Artif Organs. 2017; 40(10):550-7.

35 Bac DJ, van Blankenstein M, de Marie S, Fieren MW. Peritonitis following endoscopic polypectomy in a peritoneal dialysis patient: the need for antibiotic prophylaxis. Infection. 1994;22(3):220-1.

36 Gayen S, Ziemba Y, Jaiswal S, Frank A, Brahmbhatt Y. CDC Group EO-4 and Candida tropicalis peritonitis in a patient on peritoneal dialysis after upper endoscopy, colonoscopy and coil embolization of the gastroduodenal artery. Case Rep Gastroenterol. 2016;10(3):728-32.

37 Rains CP, Bryson HM, Peters DH. Ceftazidime. An update of its antibacterial activity, pharmacokinetic properties and therapeutic efficacy. Drugs. 1995;49(4):577-617.

38 Wu HH, Li IJ, Weng CH, Lee CC, Chen YC, Chang MY, et al. Prophylactic antibiotics for endoscopy-associated peritonitis in peritoneal dialysis patients. PLoS One. 2013;8(8): e71532.

39 Piraino B, Bernardini J, Brown E, Figueiredo A, Johnson DW, Lye WC, et al. ISPD position statement on reducing the risks of peritoneal dialysis-related infections. Perit Dial Int. 2011;31(6):614-30. 
40 ASGE Standards of Practice Committee; Khashab MA, Chithadi KV, Acosta RD, Bruining $\mathrm{DH}$, Chandrasekhara V, et al. Antibiotic prophylaxis for GI endoscopy. Gastrointest Endosc. 2015;81(1):81-9.

41 Bratzler DW, Dellinger EP, Olsen KM, Perl TM, Auwaerter PG, Bolon MK, et al. Clinical practice guidelines for antimicrobial prophylaxis in surgery. Am J Health Syst Pharm. 2013;70(3):195-283.

42 Nelson RL, Gladman E, Barbateskovic M. Antimicrobial prophylaxis for colorectal surgery. Cochrane Database Syst Rev. 2014(5): CD001181.

43 Grant SW, Hopkins J, Wilson SE. Operative site bacteriology as an indicator of postoperative infectious complications in elective colorectal surgery. Am Surg. 1995;61(10): 856-61.

44 Fein PA, Madane SJ, Jorden A, Babu K, Mushnick R, Avram MM, et al. Outcome of percutaneous endoscopic gastrostomy feeding in patients on peritoneal dialysis. Adv Perit Dial. 2001;17:148-52.
45 Dorman RM, Benedict LA, Sujka J, Sobrino J, Dekonenko C, Andrews W, et al. Safety of laparoscopic gastrostomy in children receiving peritoneal dialysis. J Surg Res. 2019;244:460-7.

46 Rahnemai-Azar AA, Rahnemaiazar AA, Naghshizadian R, Kurtz A, Farkas DT. Percutaneous endoscopic gastrostomy: indications, technique, complications and management. World J Gastroenterol. 2014;20(24):7739-51.

47 Warady BA, Bashir M, Donaldson LA. Fungal peritonitis in children receiving peritoneal dialysis: a report of the NAPRTCS. Kidney Int. 2000;58(1):384-9.

48 Machuca E, Ortiz AM, Rabagliati R. Streptococcus viridans-associated peritonitis after gastroscopy. Adv Perit Dial. 2005;21:60-2.

49 Chen CC, Huang MT, Wei PL, Liang HH, Chen $\mathrm{SC}, \mathrm{Wu} \mathrm{CH}$, et al. Severe peritonitis due to Streptococcus viridans following adjustable gastric banding. Obes Surg. 2010;20(11): 1603-5.

50 Fan PY, Chan MJ, Lin SH, Wu HH, Chang MY, Tian YC, et al. Prophylactic antibiotic reduces the risk of peritonitis after invasive gynecologic procedures. Perit Dial Int. 2019 JulAug;39(4):356-61.
51 Ma TL, Wang CT, Hwang JC. Recurrent peritonitis episodes in a continuous ambulatory peritoneal dialysis patient after gynecologic procedures. Perit Dial Int. 2012;32(1):113-4.

52 Sobel JD, Fisher JF, Kauffman CA, Newman CA. Candida urinary tract infections: epidemiology. Clin Infect Dis. 2011;52(Suppl 6): S433-6.

53 Li PK, Leung CB, Leung AK, Luk WK, Lai KN. Posthysteroscopy fungal peritonitis in a patient on continuous ambulatory peritoneal dialysis. Am J Kidney Dis. 1993;21(4):446-8.

54 Maruyama H, Nakamaru T, Oya M, Miyakawa Y, Sato N, Ishizuka Y, et al. Posthysteroscopy Candida glabrata peritonitis in a patient on CAPD. Perit Dial Int. 1997;17(4):404-5.

55 ACOG practice bulletin No. 195: prevention of infection after gynecologic procedures. $\mathrm{Ob}$ stet Gynecol. 2018;131(6):e172-e89.

56 Dimitriadis CA, Bargman JM. Gynecologic issues in peritoneal dialysis. Adv Perit Dial. 2011;27:101-5. 